\title{
Psychological and Family Factors Associated with Suicidal Ideation in Pre-Adolescents
}

\author{
Ferran Viñas ${ }^{1}$, Josepa Canals ${ }^{2}, \mathrm{M}^{\mathrm{a}}$ Eugenia Gras ${ }^{1}$, Claudia Ros ${ }^{3}$, and Edelmira Domènech-Llaberia ${ }^{3}$ \\ ${ }^{1}$ University of Girona \\ ${ }^{2}$ Rovira i Virgili University \\ ${ }^{3}$ Autonomous University of Barcelona
}

\begin{abstract}
To assess the psychological and family factors associated with suicidal ideation in preadolescent children, we studied a sample of 361 students, average age 9 years old. Two groups were formed, on the basis of the presence $(n=34)$ or absence $(n=44)$ of suicidal ideation. Suicidal ideation was assessed with the Children's Depression Inventory and the Children's Depression Rating Scale-Revised. Depression, hopelessness, self-esteem, and perceived family environment were compared in both the suicidal ideation and the control groups. Students with suicidal ideation generally presented greater depressive symptoms and hopelessness, and lower self-esteem and family expressiveness, although there were differences both between sexes, and when the variable depression was controlled. Identifying these risk factors in pre-adolescents may have an impact on prevention of suicidal behavior at higher risk ages.

Key words: suicidal ideation, children, depression, hopelessness, self-esteem and perceived family environment
\end{abstract}

Con el objetivo de evaluar factores psicológicos y familiares asociados a la ideación suicida en niños prepúberes, se ha utilizado una muestra de 361 escolares con una edad media de 9 años, a partir de la cual se han constituido 2 grupos en función de la presencia $(n=34)$ o ausencia de ideación suicida $(n=44)$. La ideación suicida se ha evaluado con el Children's Depression Inventory y la Children's Depression Rating Scale Revised. La depresión, la desesperanza, la autoestima y la percepción del clima familiar se han comparado en el grupo con ideación suicida y el grupo control. Los alumnos con ideación suicida presentan en general mayor sintomatología depresiva, mayor desesperanza y menor autoestima y expresividad familiar, aunque existen diferencias según sexo y depresión. La identificación de estos factores de riesgo en prepúberes puede ser importante en la prevención de la conducta suicida en edades de mayor vulnerabilidad.

Palabras clave: ideación suicida, niños, depresión, desesperanza, autoestima, ambiente familiar percibido

Correspondence concerning this article should be addressed to Dr. Ferran Viñas Poch, Dto. de Psicología, Universitat de Girona. Plaça Sant Domènech, 9. 17071- Girona (Spain). E-mail: ferran.vinas@udg.es 
The wish to die and thoughts of killing oneself (suicidal ideation) are a frequent phenomenon among schoolchildren. Recent epidemiological studies have revealed a high prevalence of suicidal ideation in "normal" children between 6-12 years of age. This prevalence falls between $8.9 \%$ (Pfeffer, Zuckerman, Plutchik, \& Misruchi, 1984) and 32.2\% (Bandim, Fonseca, \& De Lima, 1997). This percentage may vary according to sex and the characteristics of the academic institution (Viñas \& Domènech-Llaberia, 1997).

Suicidal ideation is the first link or lowest level of suicidal behavior. It is unlikely that at these ages children may develop suicidal behavior, or that it may intensify and lead to attempted suicide or to suicide itself. Nonetheless, there is sufficient data to verify such behavior at early ages. In our country, for example, there are records of a case of suicide at 6 years of age (Cobo, 1986). In the study by Groholt, Ekeberg, Wichstrom, and Haldorssen (1998), 10.8\% of suicides in the Norwegian teenage population were committed by children under 15 years of age. In this group, there were suicides by 8- and 10-year-old children. These data are related to the rate of suicide attempts among children and adolescents. According to Marcelli (1978), out of the total of suicide attempts in the population under 18 years of age, between 10 and $15 \%$ are carried out by children. It is precisely during adolescence that both the risk of attempted suicide and suicide increase considerably (Mardomingo, 1995; National Center for Health Statistics, 2000; Pfeffer, 1986).

The severity of suicidal ideation lies in its persistence or temporary stability. Some studies (e.g., Pfeffer et al., 1984), seem to indicate that there is some stability in a considerable percentage of cases, specifically $50 \%$, at a 2 -year follow-up. Domènech-Llaberia, Canals, and Fernández-Ballart (1992) observed that $27 \%$ of girls and $18.4 \%$ of boys maintained these ideas at a 3-year follow-up. It seems reasonable to assume from these data that these children, in whom suicidal ideation persists, have a greater probability of developing more serious suicidal behavior when they reach adolescence. If effective prevention programs for schoolchildren were developed, the alarming rates that identify suicide as one of the main causes of mortality among the young would decrease (King, 1999; Pfeffer, 1986). For this purpose, we must first know which risk factors are associated with suicide. Moreover, this information should be gathered from the study of children from a normal school population, who, after all, will be the main target of all the efforts for the prevention of suicide behavior and psychopathology (Flisher, 1999; World Health Organization, 2000). The results from some research (Cotton \& Range, 1993) indicate this, as the characteristics of populations with psychiatric pathology and those of school populations do not appear to be totally similar.

Most studies agree on the existence of a close relation between depression and suicide (Goldston et al., 1999; Groholt et al., 1998; Groholt, Ekeberg, Wichstrom, \& Haldorssen, 2000; Shaffer et al., 1996) and suicidal ideation (De Man \& Leduc, 1995; Domènech-Llaberia et al., 1992), and that this relationship becomes stronger as individuals get older (Mardomingo, 1995; National Center for Health Statistics, 2000; Pfeffer, 1986). Suicidal ideation is a symptom of depression, but many children who meet all the diagnostic criteria of depression do not manifest it. Likewise, not all individuals with suicidal ideation suffer from depression. Carlson and Cantwell's (1982) research clearly identified three groups of children: children who suffer from depression and suicidal ideation, children who suffer from depression but do not present suicidal ideation, and children with suicidal ideation who do not suffer from depression. However, there seems to be a close relationship between depression and suicidal ideation.

From a cognitive perspective, two constructs hopelessness and self-esteem-are modulating variables of suicidal behavior. These two variables, along with a negative perception of the environment, constitute the three essential elements (negative triad) of Beck's (1976) cognitive theory of depression. The first, hopelessness, has been seriously considered as one of the best predictors or indicators of the risk of suicidal behavior. Results from different sources (Asarnow \& Guthrie, 1989; Cotton \& Range, 1996; Kashani, Reid, \& Rosenberg, 1989; Morano, Cisler, \& Lemerond, 1993) seem to indicate a clear link between hopelessness and suicidal behavior. Furthermore, hopelessness is seen to correlate more consistently with attempted suicide than does depression (Kazdin, French, Unis, Esveldt-Dawson, \& Sherick, 1983). However, in some cases, the exact opposite has been reported (Asarnow, Carlson, \& Guthrie, 1987). The results for self-esteem are not so clear, although individuals who manifest or act out suicidal behavior are frequently seen to possess lower self-esteem (De Man, Leduc, \& Labrèche-Gauthier, 1993; Marciano \& Kazdin, 1994).

Family environment is a very important factor when analyzing the possible mechanisms that lead to the development of suicidal behavior. Tension and family conflict are identified as risk factors for suicidal behavior in children. When perception of family environment has also been studied, family disorganization, conflict, and lack of control, cohesion, and expressiveness have been observed as common factors in the family backgrounds of children who develop suicidal behavior (Asarnow, 1992; Asarnow et al., 1987; Campbell , Milling, Laughlin, \& Bush, 1993).

The purpose of this study is to examine whether there are any risk factors associated with suicidal ideation in preadolescent children. We expect to find that the children with suicidal ideation will have more depression and family conflict and lower self-esteem than those who do not present suicidal ideation. Also, in accordance with Carlson and Cantwell (1982), some children will present suicidal ideation in absence of depression. We analyzed various psychological and family variables in a sample of schoolchildren, average age 9 years old. Data was differentiated by sex and compared with other studies of adolescents and with those of adolescents with severe suicidal behavior. 


\section{Method}

\section{Participants}

We studied two groups of schoolchildren between the ages of 8 and 12 , mean age $9(S D=0.95)$. The first group was made up of children with suicidal ideation (20 boys and 14 girls), and the second was a control group (21 boys and 23 girls). These groups were formed on the basis of the results of an epidemiological study of suicidal ideation in school-age children. In the first phase, 181 boys and 180 girls were randomly selected from public and private primary schools in the area of Girona (an area of Catalonia, Spain, with above-average socioeconomic status). For this, we used cluster sampling, with the classroom as the cluster. Stratification was done by geographical location (rural, less than 2,000 inhabitants; semi-urban, between 2,000 and 10,000 inhabitants, and urban, more than 10,000 inhabitants) and school year (third, fourth, and fifth grades). The resulting sample corresponded to $7.38 \%$ of the population studied, and participation of the selected students was $98.4 \%$.

\section{Instruments}

Children's Depression Inventory (CDI; Kovacs, 1983). This instrument is one of the most widely used assessments of depressive symptoms in children between 8 and 17 years of age. It is made up of 27 items, each of which has three possible responses. The child must indicate the one which best describes his or her situation during the previous two weeks. The scores in each item range between 0 and 2 , depending on the intensity of the symptom. Thus, the minimal total score is 0 and the maximal score is 54 . In this study, we used the Catalan version created by the Psychology Department of the Autonomous University of Barcelona. The psychometric properties of this version, that is, internal consistency $(\alpha=.75)$ and its correlation with other measures of depression (Monreal, 1988), are acceptable.

Hopelessness Scale for Children (HSC; Kazdin, et al., 1983). This instrument is a version of Beck, Weissman, Lester, and Trexler's (1974) Hopelessness Scale, adapted for children. It is made up of 17 items with dichotomic responses, in which those denoting hopelessness score points. This way, a high total score (maximum 17) indicates that the individual holds a negative view of the future. With the authors' consent, we translated the scale into Catalan and adapted it. Although it does not present a very high internal consistency $(\alpha=.58)$ for the entire population studied, this increases to $a=.71$ when only the group with depressive symptoms is analyzed (Viñas \& Domènech-Llaberia, 1998).

Children's Depression Rating Scale-Revised (CDRS-R; Poznansky et al., 1984). This scale is a semi-structured interview made up of 18 items. Its main purpose is to evaluate the intensity of depression in children between the ages of 6 and 12. From the 18 items that make up the scale,
4 assess the behavior of the child during the interview, and the remaining 14 report the child's affective state. According to symptom severity, the scores of the items range from 1 to 7, except for items 4 (sleep), 5 (appetite), 16 (speech tempo), and 17 (hypoactivity). In these items, the maximal score was 5. The total scale score ranges from 18 (minimum) to 118 (maximum). The Spanish version of CDRS-R employed correlates significantly and positively with other measures of depression, such as CDI and ESDM, and it is a reliable scale: $\alpha=.87$ (Domènech-Llaberia \& Polaino, 1990). It was basically used to evaluate the intensity of depressive symptoms, and to corroborate suicidal ideation previously detected with the CDI.

Culture-Free Self-Esteem Inventory for Children (CultureFree SEI; Battle, 1981). This self-esteem inventory is made up of 30 items, each with two possible responses. Scores vary between 0 and 30 . High scores indicate that the child has a good opinion of him- or herself. We used the Spanish version of form B (an experimental translation carried out by a pychologist and reviewed by a bilingual linguist), which has good internal consistency $(\alpha=.79)$ and a significant correlation at the 1-year follow-up, $r=.71$ (Arrufat, 1997).

Family Environment Scale (FES; Moos \& Moos, 1981). The Spanish adaptation of this scale only contemplates one of the three applications of the original scale. This version records how individuals feel about their family environment. Although the scale is designed to be used with adolescents and adults, it may also be administered to children. It is made up of ten subscales, grouped into three areas of family interaction: relationships, development, and stability. However, in our research, only four subscales were used: Cohesion (CO: the extent to which members of a family understand and help each other), Expressiveness (EX: the extent to which members of a family are allowed to act freely and express their feelings), Conflict (CT: the extent to which anger, aggression and conflict among members may be freely and openly expressed), and Control (CN: the extent to which development of family life is bound by rules and established procedures). Each item is rated true or false, with the scores in each of the subscales ranging from 0 to 9 (maximum score). The Spanish version shows high reliablity, with test-retest correlations in the four subscales used ranging from .73 (expressivenes) to .86 (cohesion). Alpha coefficients ranged between .67 (control) and .78 (cohesion).

Wechsler Intelligence Scale for Children (WISC; Wechsler, 1949). We administered the Catalan version of this scale. Because of the excessively long administration time required, and the fact it should be applied individually, we decided to use only three of its subscales: cubes, comprehension, and similarities. The typical scores for these three scales vary between 1 and $20(M=10, S D=3)$. The internal consistency coefficients of the Catalan version employed were .57 (comprehension), .83 (similarities), and .87 (cubes). 
Four Factor Index of Social Status (Hollingstead, 1975). This instrument provides an index of socio-economic level according to four factors: Marital status, Occupation, Education, and Retirement. This information was gathered in the form of a personal-data questionnaire (Spanish translation) administered to parents. The status score of a nuclear family unit is calculated by multiplying the scale value for Occupation by a weight of 5 and the scale value for Education by a weight of 3 (the overall factor weights were calculated with multiple regression equations). The resulting computed scores ranged from 66 (high) to 8 (low).

Operational definition of diagnosis of depression. Using the CDRS-R items, the Diagnostic and Statistical Manual of Mental Disorders, $4^{\text {th }}$ edition (American Psychiatric Association, 1994) diagnostic criteria corresponding to major depression and dysthymia were detected. The criteria for establishing a diagnosis of depression used in this research (according to the CDRS-R) were the same as those of another study of child depression in Spain (Polaino \& DomènechLlaberia, 1993). Consequently, a score of 4 or more in one of the CDRS-R items that correspond to DSM-IV diagnostic criteria was considered to indicate the presence of a symptom. However, given that no case follow-up to verify the persistence of symptoms could be performed after the 1-year interval, the diagnosis of dysthymia cannot be considered definite. In any case, by dysthymic disorder, we refer to the presence of the particular symptoms of the disorder in a cross sectional study, and do not include the aspect of time.

\section{Procedure}

In the first phase, the CDI was used to identify children with suicidal ideation, using item 9 , which has, as all the other CDI items, three possible responses. The first response $(0=I$ do not think about killing myself $)$ corresponds to absence of ideation, whereas the second $(1=$ I think about killing myself, but I wouldn't do it) and the third ( 2 = I want to kill myself) indicate, respectively, suicidal ideation and intention. In the second phase (approximately one month after the first phase), all children who had scored 1 or more on item 9 of the CDI $(n=49)$, or who had not responded to item $9(n=3)$ were individually evaluated with the CDRS$\mathrm{R}(n=52)$. We used item 13 of the CDRS-R, with scores of 4 or over (as the author suggests for all items) to identify and thus form the suicidal ideation group. Children who, according to the CDRS-R, no longer presented suicidal ideation at the second phase $(n=13)$ were excluded from the group (in which suicidal ideation had previously been detected). At the same time, we randomly selected from those children who had scored 0 on item 9 of the CDI, the same number as the number of children who had been identified as possible cases of ideation. These made up the control group $(n=52)$. In this second phase, we administered the WISC, the HSC, the FES, and the Culture-Free SEI to both the risk and control groups. The Four Factor Index of Social
Status was also administered to their parents. Subsequently, children whose intelligence test results were significantly below the norm (standard score equal or less than 7 in the three WISC sub-tests: similarities, comprehension, and cubes) were eliminated from both groups (1 from the ideation group and 4 from the control group), as were those who did not fill in all the assessment tests ( 1 from the ideation group and 4 from the control group). In short, the suicidal group was made up of 34 children and the control group of 44 children.

\section{Statistical Analyses}

For the statistical analysis of the data, we used the SPSS, version 6.0, with three data analyses. In the first analysis, the equivalence of the two groups under study was verified, so that subsequently, in a second analysis, the results obtained in each group could be compared. A third analysis controlled the variable depression. The two initial groups, control and suicidal ideation, were divided into two subgroups: one with and one without depressive symptoms. Since the number of individuals was not very high, and the number of children with a diagnosis of depression was quite low, we used quantitative criteria to establish these groups. Usually, standard criteria (i.e., two standard deviations above the mean) would be applied. If this had been done, we would have encountered the same problem as with the diagnosis of depression. We therefore chose the mean, plus one standard deviation, as the differentiating criteria. Those participants with a score equal to or higher than the mean plus one standard deviation in CDRS-R (30 points) were considered to have depressive symptoms. The rest, whose scores were below 30, were considered to be without depressive symptoms.

In all the data analyses, we used ANOVA to compare the means. The total score of the CDRS-R was calculated excluding item 13, which was used to identify suicidal ideation. In order to eliminate the influence of depression on self-esteem, hopelessness, and family environment variables, an analysis of covariance was carried out with the total CDRS-R (depression) scores as the covariable. In the case of nominal values, for example in the diagnosis of depression, we used Chi-square, accepting values with a $p$ lower than .05 as statistically significant. Also, when the homogeneous variance requisite was not met, we applied the Kruskal-Wallis nonparametric test.

\section{Results}

Analysis of the Groups

The prevalence of suicidal ideation in item 9 of the CDI was $13.6 \%$ (10.5\% of the girls and $16.8 \%$ of the boys). Out of this, $10.3 \%$ ( $8.3 \%$ of the girls and $12.3 \%$ of the boys) corresponded to ideation, whereas $3.3 \%$ corresponded to intention (2.2\% of girls and $4.5 \%$ of boys). This prevalence 
was confirmed a month later by $67.3 \%$, with the information from item 13 of the CDRS-R. This group of participants and a control group without suicidal ideation were first analyzed to verify their equivalence with regard to age, sex, school grade, intellectual level, and socio-economic level. Although these groups did not differ significantly in terms of age, $85.3 \%$ of the children classified as having suicidal ideation and $77.3 \%$ of the controls were over 9 years old, in contrast to the group of children under 9 , in which there were only $14.7 \%$ of children with suicidal ideation and $22.7 \%$ of controls. There were no statistically significant differences in the three WISC subscales used to assess intellectual level, or in the other socio-demographic variables. The two groups were therefore considered to be equivalent in these variables.

\section{Suicidal Ideation and Depression}

Table 1 shows the averages for each group (control and suicidal ideation) in the CDRS-R. An ANOVA showed that the CDRS-R scores (excluding item 13) in the group of boys and girls with suicidal ideation were significantly higher than those of the control group.

In diagnosing depression with DSM-IV criteria, we detected a higher number of dysthymic disorders in the group of children with suicidal ideation $(32.4 \%)$ than in the control group $(6.8 \%), \chi^{2}(1, N=78)=8.49, p=.004$. None of the children evaluated in the general population $\left(1^{\text {st }}\right.$ phase $)$ met the diagnostic criteria for major depression. $78 \%(11 / 14)$ of the cases tentatively diagnosed as having a dysthymic disorder were children with suicidal ideation. These results indicate that depressive disorders are more frequent in children with suicidal ideation than in children who do not have suicidal ideation.

\section{Suicidal Ideation, Hopelessness, and Self-Esteem}

As can be seen in Table 2, the scores of schoolchildren with suicidal ideation in the hopelessness scale were significantly higher than those of the control group. However, when the scores were analyzed by sex, it was seen that boys with suicidal ideation were more lacking in hope, $F(1,39)$ $=7.14, p=.0109$, than were the girls. Girls in both groups had a similarly positive view of the future, $F(1,35)=0.10$, $p=.7581$. Both groups presented the same level of selfesteem, $F(1,76)=0.85, p=.358$, and no statistically significant differences were found between boys and girls.

Analysis of covariance showed that depression did not affect the hopelessness scores in boys, $F(1,40)=0.885, p$ $=.353$. However, in girls, hopelessness was accounted for by depression, $F(1,36)=8.55, p=.006$, but not by suicidal ideation, $F(1,36)=1.08, p=.305$. Covariance analysis also revealed a depression effect on girls' self-esteem scores, $F(1,36)=14.32, p<.001$, but not a suicidal ideation effect.

\section{Suicidal Ideation and Family Environment}

As seen in Table 2, children's perception of their family environment was similar in both groups. When data was analyzed separately by sex, however, it became apparent that boys with suicidal ideation described their family life more frequently in terms of excessive control, $F(1,39)=5.56, p$ $=.024$. This refers to a family environment characterized by respect for rules and established procedures. Also, although not statistically significant, more conflict was reported within the family environment of boys in the suicidal ideation group than in the control group, $F(1,39)=2.57, p=.117$. Furthermore, covariance analysis revealed no effect of depression on boys' family control scores, $F(1,40)=1.39$, $p=.245$. Depression significantly accounted for boys' expressiveness scores, $F(1,40)=5.10, p=.030$, but no suicidal ideation effect was revealed, $F(1,77)=7.97, p=.006$.

\section{Results when Controlling the Depression Variable}

On the basis of the CDRS-R, the two groups, "without depressive symptoms" and "with depressive symptoms," were created. From the presence or absence of suicidal ideation in these groups, four types of scoring of the variables were

Table 1

Group and Sex Differences in the Children's Depression Rating Scale-Revised (CDRS-R) with regard to Suicidal Ideation

\begin{tabular}{|c|c|c|c|c|c|c|c|}
\hline \multirow[t]{2}{*}{ Variable } & & \multicolumn{2}{|c|}{$\begin{array}{l}\text { Control Group } \\
\qquad \begin{array}{c}(n=44) \\
\text { girls }=23 \\
\text { boys }=21\end{array}\end{array}$} & \multicolumn{2}{|c|}{$\begin{array}{l}\text { Suicidal Ideation Group } \\
\qquad \begin{array}{c}(n=34) \\
\text { girls }=14 \\
\text { boys }=20\end{array}\end{array}$} & \multirow[b]{2}{*}{$F$} & \multirow[b]{2}{*}{ df } \\
\hline & & $M$ & $S D$ & $M$ & $S D$ & & \\
\hline \multirow[t]{3}{*}{ CDRS-R } & & 23.98 & 6.4 & 31.38 & 10.6 & $14.59 * * *$ & 1,76 \\
\hline & Girls $(n=37)$ & 22.96 & 4.5 & 32.00 & 13.0 & $9.39 * *$ & 1,35 \\
\hline & Boys $(n=41)$ & 25.10 & 7.9 & 30.95 & 8.9 & $4.95 *$ & 1,39 \\
\hline
\end{tabular}

Note: CDRS-R total score was calculated excluding item 13.

$* p<.05 . * * p<.01 . * * * p<.001$. 
Table 2

Group and Sex Differences in the Self-Esteem, Hopelessnes, and Perceived Family Environment

\begin{tabular}{|c|c|c|c|c|c|c|c|}
\hline \multirow[t]{2}{*}{ Variable } & & \multicolumn{2}{|c|}{$\begin{array}{l}\text { Control Group } \\
\qquad \begin{array}{c}(n=44) \\
\text { girls }=23 \\
\text { boys }=21\end{array}\end{array}$} & \multicolumn{2}{|c|}{$\begin{array}{l}\text { Suicidal Ideation Group } \\
\qquad \begin{array}{c}(n=34) \\
\text { girls }=14 \\
\text { boys }=20\end{array}\end{array}$} & \multirow[b]{2}{*}{$F$} & \multirow[b]{2}{*}{ df } \\
\hline & & $M$ & $S D$ & $M$ & $S D$ & & \\
\hline \multirow[t]{3}{*}{ SELF-ESTEEM } & & 20.80 & 3.1 & 19.91 & 5.2 & 0.85 & 1,76 \\
\hline & Girls & 21.43 & 3.0 & 20.21 & 5.5 & 0.76 & 1,35 \\
\hline & Boys & 19.67 & 3.2 & 19.70 & 5.1 & 0.00 & 1,39 \\
\hline \multirow[t]{3}{*}{ HOPELESSNESS } & & 4.27 & 2.0 & 5.59 & 3.0 & $5.22 *$ & 1,76 \\
\hline & Girls & 4.61 & 1.9 & 4.86 & 2.9 & 0.10 & 1,35 \\
\hline & Boys & 3.90 & 2.1 & 6.10 & 3.0 & $7.14 *$ & 1,39 \\
\hline \multicolumn{8}{|c|}{ FAMILY ENVIRONMENT } \\
\hline \multirow[t]{3}{*}{ Cohesion } & & 7.16 & 1.8 & 7.29 & 1.6 & 0.73 & 1,76 \\
\hline & Girls & 7.57 & 1.5 & 7.50 & 1.2 & 0.02 & 1,35 \\
\hline & Boys & 6.71 & 1.9 & 7.15 & 1.8 & 0.53 & 1,39 \\
\hline \multirow[t]{3}{*}{ Expressiveness } & & 4.89 & 1.4 & 4.50 & 1.6 & 0.27 & 1,76 \\
\hline & Girls & 5.13 & 1.5 & 4.43 & 1.6 & 1.83 & 1,35 \\
\hline & Boys & 4.62 & 1.3 & 4.55 & 1.6 & 0.88 & 1,39 \\
\hline \multirow[t]{3}{*}{ Conflict } & & 2.70 & 1.7 & 3.03 & 1.9 & 0.45 & 1,76 \\
\hline & Girls & 2.87 & 1.8 & 2.36 & 1.4 & 0.77 & 1,35 \\
\hline & Boys & 2.52 & 1.7 & 3.50 & 2.2 & 2.57 & 1,39 \\
\hline \multirow[t]{3}{*}{ Control } & & 4.57 & 1.7 & 5.03 & 1.7 & 0.25 & 1,76 \\
\hline & Girls & 4.60 & 1.8 & 4.07 & 1.7 & 0.81 & 1,35 \\
\hline & Boys & 4.52 & 1.7 & 5.70 & 1.4 & $5.56^{*}$ & 1,39 \\
\hline
\end{tabular}

$* p<.05$.

compared. There was a general similarity among children without depressive symptoms, either with or without suicidal ideation. Statistically significant differences were observed between the group having both suicidal ideation and depressive symptoms and the groups without depressive symptoms. Students with both suicidal ideation and depression displayed significantly lower self-esteem $F(3,74)$ $=6.27, p<.001$, and degree of expression within the family, $F(3,74)=4.22, p<.01$, and more hopelessness $F(3,74)=$ $4.09, p<.01$, than the control group without depression.

The control group with depressive symptoms presented lower level of family cohesion. Comparisons of the four groups with Sheffé's test showed no statistical differences in terms of conflict. However, the control group without depression obtained lower scores than other groups in the conflict scale $t(74)=2.37, p=.02$.

\section{Discussion}

This study analyzed possible risk factors in suicidal ideation in a non-clinical sample of pre-adolescents. Few epidemiological studies in the general population have explored suicidal behavior in samples of non-adolescents.
This age group, not associated with high risk, was chosen to examine similarities with adolescents with suicidal behavior. Although the study is limited, in that the sample is quite small and that other psychopathological evaluations may be missing, it gathers data that may be relevant for prevention of suicide.

If the prevalence rates of suicidal ideation, using item 9 from the CDI, are compared in other Spanish sample of pubertal children (Domènech-Llaberia et al., 1992), an increase as a function of age is observed. However, although at 9 years, this rate was lower than in early adolescence, it nonetheless is still noteworthy in this age group.

Our results corroborate the relationship between depression and suicidal ideation in children. This supports data from numerous authors who found that there is a greater risk of suicide in adolescents with affective disorders (Goldston et al., 1999; Groholt et al., 1998, 2000). De Man and Leduc (1995) also identified depressive symptoms as the best predictor of suicidal ideation in schoolchildren between the ages of 12 and 18. However, although we observed this relationship to be higher in females than in males, those authors did not find that sex significantly contributed to the prediction. For cases of suicide, Shaffer et al. (1996) found that mood disorders were more common 
in girls than in boys, which suggests that the association found in our study could be considered an early risk factor for suicidal behavior.

However, as the statistical analysis of the data has shown, about one third of the children with suicidal ideation did not present depressive symptoms, so that there were two groups of school children with suicidal ideation. The first group was characterized by the absence of symptoms of depression and hopelessness, an adequate level of self-esteem, and a perception of their family environment as offering communication and free expression of feelings. In these students, suicidal thoughts or ideas may be learned, and thus be one of the many responses that make up their habitual response repertoire when facing difficult situations. Anyhow, it is important to verify this assumption with further research, analyzing other associated psychopathological characteristics, and carrying out a longitudinal follow-up of the children to confirm the stability of suicidal ideation. The second group was made up of schoolchildren who presented suicidal ideation associated with depressive states or depressive symptoms, as well as other characteristics that vary according to sex. In boys, these features were feelings of hopelessness and a perception of greater family control. In girls, the features were lower self-esteem and the perception of a low degree of expression in the family environment. Although our results cannot be considered definite because of the sample sizes, however, they are not in accordance with the data of Overholser, Freiheit, and DiFilipo (1997), who found that depression and hopelessness were related to attempted suicide in girls (12-17 years old) but not in boys. This difference may be due to the differences between the two samples: age, level of severity of suicidal behavior, and characteristics of the individuals (psychiatric versus normal). In the work by Milling, Campbell, Bush, and Laughlin.(1996), the variables that best predicted suicide attempt differed from those that predicted suicidal ideation. It therefore seems logical to presume that the characteristics presented by individuals with suicidal behavior may differ in severity and depending on the features of the studied population.

Another important aspect is the relationship between low self-esteem and suicidal ideation, but only when depressive symptoms are present. This finding also supports the association between depression and self-esteem. In adolescents, support for the relationship between suicidal behavior and low self-esteem has been reported by De Man and Leduc (1995), who found a negative and significant correlation between suicidal ideation and self-esteem, and by Groholt et al. (2000), who observed this relationship in suicide attempts.

Family cohesion is a general characteristic in all of the students we evaluated, with the exception of the controlgroup children with depressive symptoms. All the students with depressive symptoms, regardless of whether or not they manifested suicidal ideation, also perceived that their family environment did not encourage free expression of feelings.
Therefore, although this feature has been traditionally associated with suicidal behavior (Asarnow, 1992; Asarnow et al., 1987; Campbell et al. 1993; Groholt et al., 2000), it may actually be due to a characteristic associated with depressive symptoms. Perceived family conflict, seems to be higher in persons who express suicidal ideas and/or who show depressive symptoms, which is in accordance with the results of other research (Kienhorst, Wolters, Diekstra, \& Otte, 1987; Kosky, 1983; Mitchell \& Rosenthal, 1992; Pfeffer, 1989). It should also be pointed out that children with depressive symptoms and suicidal ideation perceived their family environment as being rather rigid and strict in the compliance of rules, whereas, in other studies, the exact opposite has been found (Asarnow et al., 1987). These differences may be due both to higher severity of suicidal behavior or to higher presence of emotional/behavioral disorders observed in the referred studies. In other words, the psychological and psychopathological profile of children with suicidal ideation in general community population may be different from in- and outpatient children treated for attempted suicide and who may present associated disorders. The sex differences in our study may indicate that the boys in our sample had more severe depressive symptoms than the girls, as is supported by their higher hopelessness scores. Others studies should be carried out to confirm these results.

The results of this study support other previously published studies on suicidal behavior of adolescents and youngsters ((Dori \& Overholser, 1999; Kumar \& Steer, 1995; Mitchell \& Rosenthal, 1992; Schotte \& Clum, 1982; Steer, Kumar, \& Beck, 1993). As mentioned, suicide ideation in some cases persists and, as a consequence, it is could be assumed that some individuals may have antecedents of having presented suicidal ideation in previous stages (Doménech-Llaberia et al., 1992; Pffeffer et al., 1984). There are also similarities between children's and adolescents' suicidal ideation (Flisher, 1999, Pfeffer, 1985).

Our results also corroborate the relationship between depression and suicidal ideation, although they also reflect that, in some cases, suicidal ideation may occur in absence of depression or depressive symptomatology. As mentioned in the introduction, there is higher risk of suicide during adolescence (Mardomingo,1995; the National Center for Health Statistics, 2000; Pfeffer, 1986). Various epidemiological studies indicate that the prevalence of depression and suicide rates increase with age (Gutiérrez, 1995; Myers, Burke, \& McCauley, 1985; Torre et al., 1999; Velez \& Cohen, 1988). These studies also reveal that during childhood, the risk of consummated suicide, and even of suicide attempts, is very low, whereas during adolescence, this risk increases substantially. In fact, in developed countries, among them Spain, suicide is the third, and in some countries even the second, main cause of death among adolescents and young people.

This study shows that pre-adolescents who present suicidal ideation may have associated characteristics, 
considered risk factors, which may lead to severe suicidal behavior. These data support the existence of suicidal ideation at early ages. The evaluation of depression and cognitive and family factors should therefore be included in the study of suicidal ideation in the general population of children to prevent suicide at ages of higher risk.

\section{References}

American Psychiatric Association (1994). Diagnostic and statistical manual of mental disorders ( $4^{\text {th }}$ ed.). Washington, DC: Author. (Spanish translation: Manual diagnóstico y estadístico de los trastornos mentales. Barcelona: Masson, 1995).

Arrufat, M.T. (1997). L'autoestima a l'adolescència: Adaptació a població espanyola dels questionaris Culture-Free Self-Esteem Inventory formes $B \quad i \quad A D$; relació amb variables psicopatologiques. Unpublished doctoral dissertation, Universitat Autónoma de Barcelona.

Asarnow, J.R. (1992). Suicidal ideation and attempts during middle childhood: Associations with perceived family stress and depression among child psychiatric inpatients. Journal of Clinical Child Psychology, 21, 35-40.

Asarnow, J.R., Carlson, G.A., \& Guthrie, D. (1987). Coping strategies, self-perceptions, hopelessness, and perceived family environments in depressed and suicidal children. Journal of Consulting and Clinical Psychology, 55, 361-366.

Asarnow, J.R., \& Guthrie, D. (1989). Suicidal behavior, depression, and hopelessness in child psychiatric inpatients: A replication and extension. Journal of Clinical Child Psychology, 18, 129-136.

Bandim, J.M., Fonseca, L., \& De Lima, J.M. (1997). Prevalência da ideaçâo suicida numa populaçâo de escolares do nordeste brasileiro. Jornal Brasileiro de Psiquiatria, 46, 477-481.

Battle, J. (1981). Culture-free self-esteem inventories for children and adults. Seattle, WA: Special Child Publications.

Beck, A.T. (1976). Cognitive therapy and the emotional disorders. New York: International Universities Press.

Beck, A.T., Weissman, A., Lester, D., \& Trexler, L. (1974). The measurement of pessimism: The Hopelessness Scale. Journal of Consulting and Clinical Psychology, 42, 861-865.

Campbell, N.B., Milling, L., Laughlin, A., \& Bush, E. (1993). The psychosocial climate of families with suicidal pre-adolescent children. American Journal of Orthopsychiatry, 63, 142-145.

Carlson, G.A., \& Cantwell, D.P. (1982). Suicidal behavior and depression in children and adolescents. Journal of the American Academy of Child Psychiatry, 21, 361-368.

Cobo, C. (1986). Estadísticas y reflexiones sobre actos suicidarios en niños y adolescentes españoles. Revista de Psiquiatría y Psicología Médica, 17, 253-268.

Cotton, C.R., \& Range, L.M. (1993). Suicidality, hopelessness, and attitudes toward life and death in children. Death Studies, 17, 185-191.

Cotton, C.R., \& Range, L.M. (1996). Suicidality, hopelessness, and attitudes toward life death in clinical and nonclinical adolescents. Death Studies, 20, 601-610.
De Man, A.F., \& Leduc, C.P. (1995). Suicidal ideation in high school students: Depression and other correlates. Journal of Clinical Psychology, 51, 173-181.

De Man, A.F., Leduc, C.P., \& Labrèche-Gauthier, L. (1993). Correlates of suicidal ideation in French-Canadian adolescents: Personal variables, stress, and social support. Adolescence, 28, 819-830

Domènech-Llaberia, E., Canals, J., \& Fernández-Ballart, J. (1992). Suicidal ideation among Spanish schoolchildren: A three-year follow-up study of a pubertal population. Personality and Individual Differences, 13, 1055-1057.

Domènech-Llaberia, E., \& Polaino, A. (1990). Epidemiología de la depresión infantil. Barcelona: Espaxs.

Dori, G.A., \& Overholser, J.C. (1999). Depression, hopelessness, and self-esteem: Accounting for suicidality in adolescent psychiatric inpatients. Suicide and Life Threatening Behavior, 29, 309-318.

Flisher, A.J. (1999). Annotation: Mood disorder in suicidal children and adolescents: Recent developments. Journal of Child Psychology and Psychiatry, 40, 315-324.

Goldston, D.B., Daniel, S.S., Reboussin, D.M., Reboussin, B.A., Frazier, P.H., \& Kelley, A.E. (1999). Suicide attempts among formerly hospitalized adolescents: A prospective naturalistic study of risk during the first 5 years after discharge. Journal of the American Academy of Child and Adolescent Psychiatry, $38,660-671$.

Groholt, B., Ekeberg, O., Wichstrom, L., \& Haldorssen, T. (1998). Suicide among children and younger and older adolescents in Norway: A comparative study. Journal of the American Academy of Child and Adolescent Psychiatry, 37, 473-481.

Groholt, B., Ekeberg, O., Wichstrom, L., \& Haldorssen, T. (2000). Young suicide attempters: A comparison between a clinical and an epidemiological sample. Journal of the American Academy of Child and Adolescent Psychiatry, 39, 868-875.

Gutiérrez, J.M. (1995). El suicidio consumado en Guipúzcua, 199092. Revista de Psicologia de la Salud, 7, 33-51.

Hollingshead, A.B. (1975). Four Factor Index of Social Status. Unpublished manuscript, Yale University, New Haven, CT.

Kashani, J.H., Reid, J.C., \& Rosenberg, T.K. (1989). Levels of hopelessness in children and adolescents: A developmental perspective. Journal of Consulting and Clinical Psychology, 57, 496-499.

Kazdin, A.E., French, N.H., Unis, A.S., Esveldt-Dawson, K., \& Sherick, R.B. (1983). Hopelessness, depression, and suicidal intent among psychiatrically disturbed inpatient children. Journal of Consulting and Clinical Psychology, 51, 504510.

Kienhorts, C., Wolters, W., Diekstra, R., \& Otte, E. (1987). A study of the frequency of suicidal behavior in children aged 5 to 14 . Journal of Child Psychology and Psychiatry, 28, 153-165.

King, K.A. (1999). High school counselors often unsure about identifying teen suicide risk. American Journal of Health Behavior, 23, 457-467.

Kosky, R. (1983). Childhood suicidal behaviour. Journal of Child Psychology and Psychiatry, 24, 457-468. 
Kovacs, M. (1983). The Children's Depression Inventory: A selfrated depression scale for school-aged youngsters. Unpublished manuscript, University of Pittsburgh, PA.

Kumar, G., \& Steer, R.A. (1995). Psychosocial correlates of suicidal ideation in adolescent psychiatric inpatients. Suicide and Life Threatening Behavior, 25, 339-346.

Marcelli, D. (1978). Suicidal attempts of the child: Statistical and general epidemiological aspects. Acta Paedopsychiatrica, 43, 213-221.

Marciano, P.L., \& Kazdin, A. (1994). Self-esteem, depression, hopelessness, and suicidal intent among psychiatrically disturbed inpatient children. Journal of Clinical Child Psychology, 23, 151-160.

Mardomingo, M.J. (1995). Los intentos de suicidio. In J.R. Sacristán (Ed.), Psicopatología del niño y del adolescente (pp. 709-714). Sevilla, Spain: Publicaciones de la Universidad de Sevilla.

Milling, L., Campbell, N.B., Bush, E., \& Laughlin, A. (1996). Affective and behavioral correlates of suicidality among hospitalized preadolescent children. Journal of Clinical Child Psychology, 25, 454-462.

Mitchell, M.G., \& Rosenthal, D.M. (1992). Suicidal adolescents: Family dynamics and the effects of lethality and hopelessness. Journal of Youth and Adolescence, 21, 23-33.

Monreal, P. (1988). Estudio de la sintomatología depresiva infantil en la provincia de Gerona: análisis de algunos factores individuales y psicosociales. Doctoral dissertation. Publicaciones de la Universitat Autónoma de Barcelona, Bellaterra, Spain.

Morano, C.D., Cisler, R.A., \& Lemerond, J. (1993). Risk factors for adolescent suicidal behavior: Loss, insufficient familial support, and hopelessness. Adolescence, 28, 851-865.

Moos, R.H., \& Moos, B.S. (1981). Family Environment Scale manual. Palo Alto, CA: Consulting Psychologists Press. [Spanish translation: Siesdedos, N., de la Cruz, M.V., \& Cordero, A. (1989). Escalas de Clima Social: familia (FES). Madrid: TEA.]

Myers, K.M., Burke, P., \& McCauley, E. (1985). Suicidal behavior by hospitalized preadolescent children on a psychiatric unit. Journal of the American Academy of Child and Adolescent Psychiatry, 24, 474-480.

National Center for Health Statistics (2000). Table 8: Deaths and death rates for the leading causes of death in specified age groups, by race and sex: United States 1998. National Vital Statistics Reports 48 (11) (www.cdc.gov).

Overholser, J.C., Freiheit, S.R., \& DiFilipo, J.M. (1997). Emotional distress and substance abuse as risk factors for suicide attempts. Canadian Journal of Psychiatry, 42, 402-408.

Pfeffer, C.R. (1985). Self-destructive behavior in children and adolescents. Psychiatric Clinics of North America, 8, 215226.

Pfeffer, C.R. (1986). The suicidal child . New York: Guilford.
Pfeffer, C.R. (1989). Family characteristics and support systems as risk factors for youth suicidal behavior. Report of the Secretary's Task Force on Youth Suicide, 2, 71-79.

Pfeffer, C.R., Zuckerman, S., Plutchik, R., \& Mizruchi, M.S. (1984). Suicidal behavior in normal school children: A comparison with child psychiatric inpatients. Journal of the American Academy of Child Psychiatry, 23, 416-423.

Polaino, A., \& Domènech-Llaberia, E. (1993). Prevalence of childhood depression: Results of the first study in Spain. Journal of Child Psychology and Psychiatry, 34, 1007-1017.

Poznansky, E.O., Grossman, J.A., Buchbaum, Y., Banegas, M., Freeman, L., \& Gibbons, R. (1984). Preliminary studies of the reliability and validity of the Children's Depression Rating Scale. Journal of the American Academy of Child and Adolescent Psychiatry, 23, 191-197.

Schotte, D.E., \& Clum, G.A. (1982). Suicide ideation in a college population: A test of a model. Journal of Consulting and Clinical Psychology, 50, 690-696.

Shaffer, D., Gould, M.S., Fisher, P., Trautman, P., Moreau, D., Kleinman, M., \& Flory, M. (1996). Psychiatric diagnosis in child and adolescent suicide. Archives of General Psychiatry, 53, 339-348.

Steer, R.A., Kumar, G., \& Beck, A.T. (1993). Self-reported suicidal ideation in adolescent psychiatric inpatients. Journal of Consulting and Clinical Psychology, 61, 1096-1099.

Torre, E., Chieppa, N., Imperatori, F., Jona, A., Ponzetti, D., Usai, C., \& Zeppegno, P. (1999). Suicide and attempted in the province of Turin from 1988 to 1994: Epidemiological Analysis. European Journal of Psychiatry, 13, 77-86.

Velez, C.N., \& Cohen, P. (1988). Suicidal behavior and ideation in a community sample of children: Maternal and youth reports. Journal of the American Academy of Child and Adolescent Psychiatry. 27, 349-356.

Viñas, F., \& Domènech-Llaberia, E. (1997). Prevalencia de la ideación suicida en la población escolar infantil. Acta Pediátrica Española, 55, 525-530.

Viñas, F., \& Domènech-Llaberia, E. (1998). Versió catalana de l'escala de desesperança per a nens de Kazdin: Estudi de la seva fiabilitat i validesa. Revista de Psicología Universitas Tarraconensis, 20, 55-69.

Wechsler, D. (1949). Wechsler Intelligence Scale for Children. New York: The Psychological Corporation. [Catalan translation: Balaguer, M., Casas, J., \& Martinez, M.C. (1986). Escala d'Intelligencia Wechsler per a nens (WISC). Madrid: TEA.]

World Health Organization (2000). Preventing suicide. A resource for teachers and other school staff. Department of Mental Health. Geneva, Switzerland: W.H.O. [www.who.int/mental_health/ documents/Suicide/res-teacher_web.pdf]

Received November 2, 2000 Revision received December 14, 2001 Accepted January 9, 2002 